Rev. Colomb. Nefrol. 2017;4(2): 200 - 209 http://www.revistanefrologia.org

doi: http://dx.doi.org/10.22265/acnef.4.2.272

Reporte de caso

\title{
Glomerulonefritis rápidamente progresiva asociada a ANCA en un paciente con nefropatía por IgA, reporte de caso
}

\section{ANCA-associated rapidly progressive glomerulonephritis in a patient with IgA nephropathy, case report}

\author{
Adalberto Peña Wilches ${ }^{1}$, José de Jesús Arias Agudelo², Luis Javier Ossa Gómez³, Diana Gutiérrez González ${ }^{4}$, \\ Jorge Enrique Echeverri Sarmiento ${ }^{5}$, Carolina Larrarte Arenas, ${ }^{6, *}$
}

${ }^{1}$ Médico internista, residente de nefrología, Universidad Militar Nueva Granada, Bogotá, Colombia

${ }^{2}$ Médico patólogo, Hospital Militar Central, Bogotá, Colombia

${ }^{3}$ Médico patólogo, profesor titular de patología, Universidad Militar Nueva Granada, Bogotá, Colombia

${ }^{4}$ Residente de patología, Universidad Militar Nueva Granada, Bogotá, Colombia

${ }^{5}$ Médico internista y nefrólogo, RTS Hospital Militar Central, Bogotá, Colombia

${ }^{6}$ Médico internista y nefróloga, RTS Hospital Militar Central, Bogotá, Colombia

\begin{abstract}
Resumen
La nefropatía por IgA es la glomerulonefritis más frecuente, en la cual menos del 10\% de los pacientes cursan con deterioro rápido de la función renal. Los hallazgos histológicos de este grupo semejan los de vasculitis, con presencia de semilunas y necrosis fibrinoide. La coexistencia de nefropatía por IgA y anticuerpos anticitoplasma de neutrófilo es infrecuente y no está claro el rol patogénico de estos anticuerpos en la nefropatía por IgA. A continuación, se describe un caso de un paciente con nefropatía por IgA, glomerulonefritis rápidamente progresiva y anticuerpos anticitoplasma de neutrófilo positivos y se realiza una revisión de la literatura referente al tema.
\end{abstract}

Palabras clave: nefropatía IgA, glomerulonefritis rápidamente progresiva, vasculitis, ANCA, semilunas.

doi: http://dx.doi.org/10.22265/acnef.4.2.272

\begin{abstract}
IgA nephropathy is the most common glomerulonephritis, in which less than $10 \%$ of patients have a rapid decline of renal function. The histological findings of this group resemble those of vasculitis, with presence of crescents and fibrinoid necrosis. The coexistence of IgA nephropathy and neutrophil anti-cytoplasmic antibodies is infrequent, and the pathogenic role of these antibodies in IgA nephropathy is unclear. Here we describe a case of a patient with IgA nephropathy, rapidly progressive glomerulonephritis and neutrophil positive anti-cytoplasmic antibodies, and literature review is presented.
\end{abstract}

Key words: IgA nephropathy, rapidly progressive glomerulonephritis, vasculitis, ANCA, crescents.

doi: http://dx.doi.org/10.22265/acnef.4.2.272 progresiva asociada a ANCA en un paciente con nefropatía por IgA, reporte de caso. Rev. Colomb. Nefrol. 2017;4(2): 200-209 doi: http://dx.doi.org/10.22265/acnef.4.2.272 Correspondencia: *Carolina Larrarte Arenas, carolarrarte@hotmail.com

Recibido: 10-11-16 • Aceptado: 30-06-17 • Publicado en línea: 27-07-17 


\section{Introducción}

L La glomerulonefritis rápidamente progresiva (GNRP) es una manifestación temida de la enfermedad glomerular, ya que implica un deterioro acelerado de la función renal que marca el pronóstico de los pacientes. Menos del $10 \%$ de los pacientes con nefropatía por IgA (NIgA) tienen un curso agresivo, encontrándose, en algunos de ellos, semilunas en la biopsia renal y otros hallazgos que pueden semejar cuadros de vasculitis. Se ha reportado la presencia de anticuerpos anticitoplasma de neutrófilo (ANCA) en pacientes con NIgA, sin embargo, no está claro el rol de estos anticuerpos en la fisiopatología de la enfermedad ni en el pronóstico de los pacientes.

\section{Descripción del caso}

Paciente masculino de 49 años, con antecedente de NIgA, quien presenta cuadro de 4 semanas de rinorrea y tos seca, seguido de náuseas, sabor metálico y astenia. Refiere orina espumosa, sin hematuria macroscópica, edemas ni otro síntoma. Como antecendentes adicionales, cursa con dislipidemia mixta, hipotiroidismo y obesidad grado 1. La NIgA fue diagnosticada hace 12 años y su última valoración por nefrología fue un año atrás, encontrándose con creatinina sérica de $1,48 \mathrm{mg} / \mathrm{dL}$, tasa de filtración glomerular (CKD-EPI) en 55,4 $\mathrm{mL} / \mathrm{min} / 1,73 \mathrm{~m}^{2}$, proteinuria $250 \mathrm{mg} /$ día. Recibía enalapril y atorvastatina, sin inmunosupresores.

En la valoración, se encuentra hipertenso (155/90 $\mathrm{mmHg}$ ), sin edemas ni otro hallazgo relevante. Los paraclínicos documentan creatinina en $4,77 \mathrm{mg} / \mathrm{dL}$, hematuria, proteinuria nefrótica e hipoalbuminemia (tabla 1). Se considera lesión renal aguda KDIGO3, asociada probablemente a infección respiratoria alta, con comportamiento sugestivo de glomerulonefritis rápidamente progresiva. Se hospitaliza y se inicia metilprednisolona $500 \mathrm{mg}$ /día por 3 días.

Tabla1

Laboratorios del paciente

\begin{tabular}{|c|c|c|c|c|}
\hline Laboratorio & 1 año antes & 4 meses antes & Al ingreso & 1 día después \\
\hline Creatinina sérica-mg/dL & 1,54 & 1,59 & 4,77 & 4,97 \\
\hline Nitrógeno ureico-mg/dL & 32 & 35 & 65 & 98 \\
\hline Potasio-mEq/L & & & 5,36 & 5,7 \\
\hline Hemoglobina-gr/dL & & 12,2 & 12 & 12 \\
\hline Leucocitos/mcL & & & 6530 & \\
\hline Neutrófilos/mcL & & & 4311 & \\
\hline Linfocitos/mcL & & & 1470 & \\
\hline Albúmina sérica-gr/dL & & & 2,81 & \\
\hline Proteinuria-mg/día & 250 & & 6357 (volumen $2200 \mathrm{~mL}$ ) & \\
\hline Uroanálisis & & & DU 1020, ph 6 Proteínas 500 mg/dL, Hematuria 250, & \\
\hline $\begin{array}{l}\text { Sedimento: Eritrocitos } \\
\text { 13/CPA Leucocitos 5.5/ } \\
\text { CPA Bacterias 1+ Células } \\
\text { Epiteliales } 0-1\end{array}$ & & & & \\
\hline Gases arteriales & & & $\begin{array}{c}\text { pH 7.4 PCO2 } 25.9 \text { mmHg CHCO3 } 19 \text { mEq/L PO2 } 80 \\
\text { mmHg Sa02 } 94 \%\end{array}$ & \\
\hline
\end{tabular}


Los estudios documentan anticuerpos antinucleares (ANA), anti-DNA negativos, C3 y C4 normal y serologías para hepatitis $\mathrm{B}, \mathrm{C}, \mathrm{VIH}$ y sífilis negativas (tabla 2). Se encontraban aún pendientes resultados de ANCA y ENA. Teniendo en cuenta el deterioro de la función renal y la sospecha de glomerulonefritis rápidamente progresiva (GNRP), se inicia manejo con ciclofosfamida endovenosa $\left(1 \mathrm{gr} / \mathrm{m}^{2}\right)$. Se practicó biopsia renal cuyo reporte preliminar confirmaba la presencia de semilunas. $\mathrm{La}$ creatinina desciende lentamente hasta $2,76 \mathrm{mg} / \mathrm{dL}$ (figura 1). Se da salida hospitalaria y se continua manejo con esteroide oral en espera de resultados pendientes.

Tabla 2.

Perfil inmunológico e infeccioso

\begin{tabular}{|l|c|}
\multicolumn{1}{c|}{ Variable } & Resultado \\
\hline ANA & Negativo \\
\hline Anti-DNA & Negativo \\
\hline ENA & Negativo \\
\hline C3 & $131 \mathrm{mg} / \mathrm{dl}(81-157 \mathrm{mg} / \mathrm{dL})$ \\
\hline C4 & $43 \mathrm{mg} / \mathrm{dl}(12,90-39,20 \mathrm{mg} / \mathrm{dL})$ \\
\hline ANCA- IFI & c- ANCA negativo, p-ANCA positivo $1 / 160$ \\
\hline ANCA- ELISA & MPO 11,6 (positivo), PR3 0,5 (negativo) \\
\hline VDRL & No reactiva \\
\hline Antígeno superficie hepatitis B & Negativo \\
\hline Anticuerpo Hepatitis C & Negativo \\
\hline VIH 1 y 2 & No reactivo \\
\hline
\end{tabular}

ANA anticuerpos antinucleares, ENA anticuerpos extractables del núcleo, ANCA anticuerpos anticitoplasma del neutrófilo, IFI Inmunofluorescencia indirecta, p-ANCA patrón perinuclear, c-ANCA patrón citoplasmático, ELISA Método de inmunoadsorción ligado a enzimas, MPO mieloperoxidasa, PR3 proteinasa 3, VIH virus de la inmunodeficiencia humana

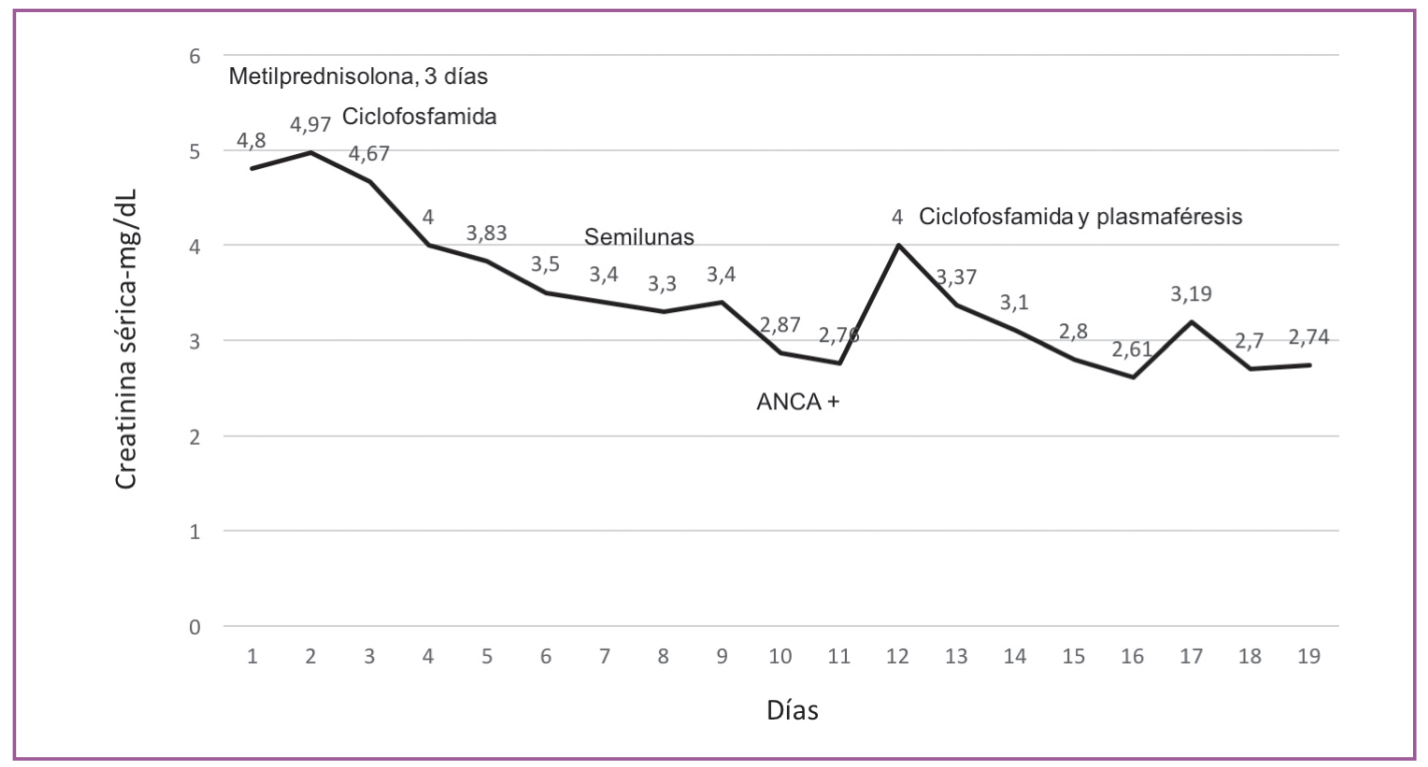

Figura 1. Evolución de la creatinina sérica en el tiempo y eventos claves durante el seguimiento del paciente. 
Cuatro días después asiste a consulta con elevación de la creatinina a 4,01 $\mathrm{mg} / \mathrm{dL}$ y con p-ANCAS positivos, confirmados con ELISA (Mieloperoxidasa, MPO 11,6) (tabla 2). Se realiza biopsia renal, que documenta 6 glomérulos a la microscopía de luz, con proliferación endocapilar leve(polimorfonucleares), proliferación extracapilar celular en más de la mitad de los glomérulos, células inflamatorias (linfocitos y plasmocitos) en el intersticio y atrofia tubular leve. No se evidencian cambios mesangiales ni vasculares (figura 2). No fue posible evaluar inmunofluorescencia por falta de material, pero se realiza inmunohistoquímica que confirma depósitos de IgA en el mesangio (figura 3). No se dispone de microscopía electrónica. Se considera que el paciente cursa con GNRP asociada a ANCAS, sin manifestaciones sistémicas extrarrenales de vasculitis.
Teniendo en cuenta los hallazgos histológicos y el deterioro renal, a pesar de haber recibido una dosis de ciclofosfamida, se decide continuar con citostático, esteroide e iniciar plasmaféresis. Se realizan 7 sesiones de plasmaféresis, presentando descenso de la creatinina hasta $2,74 \mathrm{mg} / \mathrm{dL}$ y resultando en egreso hospitalario (figura 1).

El paciente cambia su país de residencia y por lo tanto de médico tratante. Se recibe información por parte del paciente acerca de la continuidad de ciclofosfamida y esteroide. Al mes del alta hospitalaria, se realiza exámenes que documentan estabilidad de la función renal, pero persistencia de hipoalbuminemia, proteinuria y hematuria (creatinina 2,39 mg/dL, BUN $36 \mathrm{mg} / \mathrm{dL}$, albúmina $2,9 \mathrm{gr} / \mathrm{dL}$ y uroanálisis con $3+$ de proteínas y hematuria).

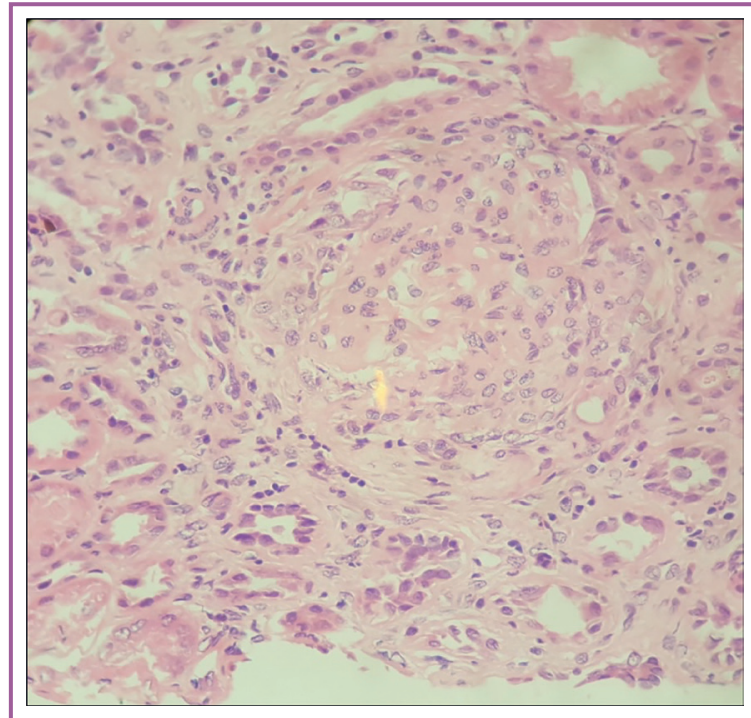

2A. Hematoxilina y eosina (400x), glomérulo con media luna celular y obliteración capilar.

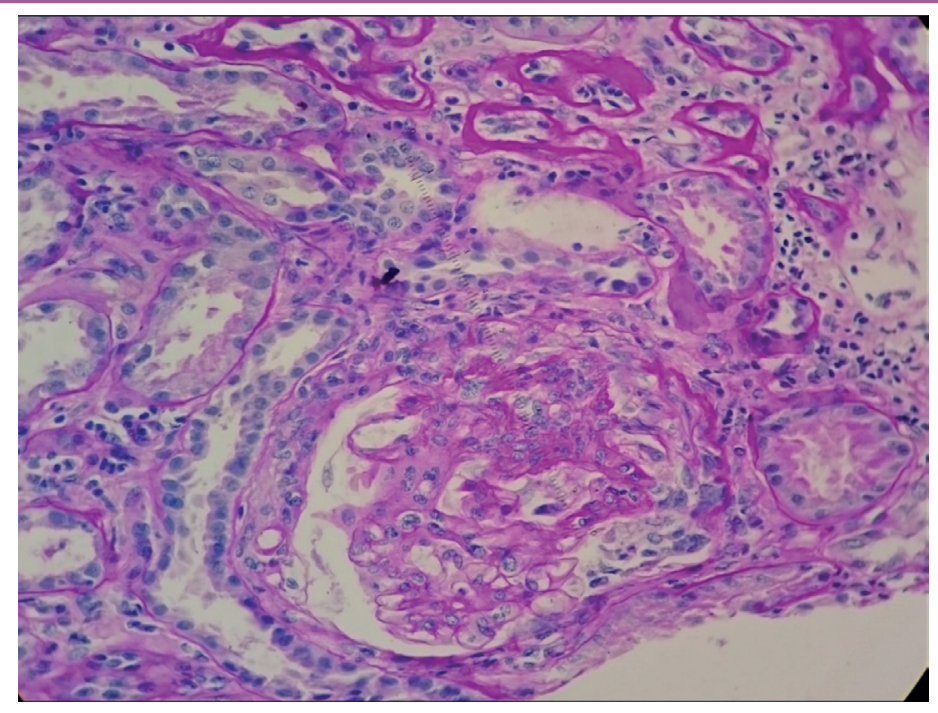

2B. PAS (400x), glomérulo con media luna celular, colapso del ovillo glomerular y engrosamiento de membranas basales tubulares.

Figura 2. Imagen de biopsia renal microscopía de luz 


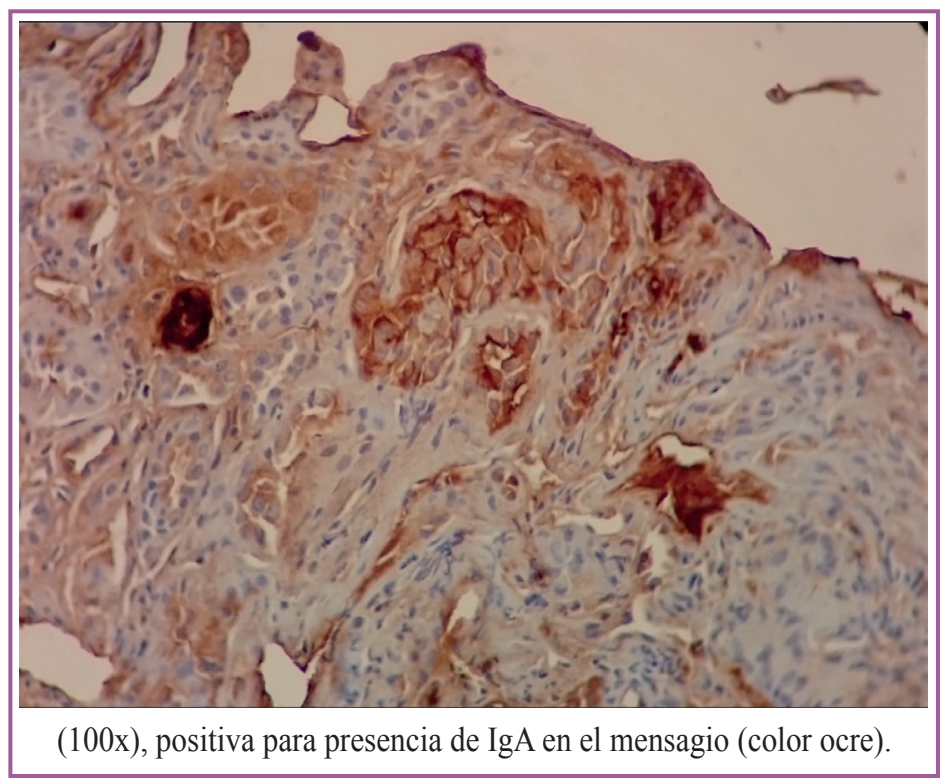

Figura 3. Imagen de biopsia renal, inmunohistoquímica.

\section{Revisión de la literatura}

La NIgA es la glomerulonefritis primaria más frecuente, caracterizada por depósito mesangial de IgA . La velocidad de progresión de la enfermedad es variable, sin embargo, a 25 años de seguimiento, el $30-50 \%$ de los pacientes progresa a enfermedad renal crónica estadio 5 (ERC5). ${ }^{2}$ Se ha reportado una progresión rápida en menos del $10 \%$ de pacientes, encontrando hallazgos histológicos sugestivos de vasculitis, como semilunas, necrosis fibrinoide y lesión arteriolar, en algunos de ellos ${ }^{3}$.

La coexistencia de anticuerpos anticitoplasma de neutrófilo (ANCA) y NIgA es rara, reportándose entre el 0,2 y $2 \%$ de los casos $^{4}$. Los ANCA, principalmente ANCA-mieloperoxidasa (MPO), se han documentado tanto en pacientes con NIgA con hallazgos histológicos de glomerulonefritis rápidamente progresiva, como en pacientes sin estos hallazgos $^{3-5}$. El tamizaje de ANCA en pacientes con vasculitis pauci-inmune generalmente se limita al estudio de inmunoglobulina G; sin embargo, se ha encontrado ANCA de clase IgA en ciertas condiciones, como púrpura de Henoch-Shonlein,
NIgA, entre otros ${ }^{6,7}$. También se ha reportado la presencia de ANCA IgA en NIgA crescéntica (NIgAc) y en glomerulonefritis crescéntica (GNc) pauci-inmune ${ }^{8-10}$. Aunque se ha evaluado el comportamiento clínico de los pacientes con NIgA y ANCA, aún no es claro el rol patogénico de estos, ya que podría tratarse de la hiperactividad de células productoras de anticuerpos u otra enfermedad concomitante $^{3}$. Es aún menos claro si la presencia de ANCA IgG o IgA tiene algún efecto diferencial.

Se han publicado varios reportes y series de caso de pacientes con NIgA y ANCA positivos ${ }^{11-16}$. Bantis y colaboradores evalúan el comportamiento de 8 pacientes con NIgA crescéntica y ANCA positivos y los comparan con 26 pacientes que presentan más de $10 \%$ de glomérulos con semilunas, pero con ANCA negativos. Todos los pacientes con ANCA cursaron clínicamente como glomerulonefritis rápidamente progresiva, alcanzando mayor nivel de creatinina en los primeros tres meses que los pacientes $\sin$ ANCA (2,2-4,2 mg/dL vs. 1,9-2,5 mg/ dL). Histológicamente, la positividad para ANCAS se relacionó con mayor porcentaje de glomérulos crescénticos (54\% vs. $18 \%)^{15}$. 
Yang y colaboradores realizan un estudio retrospectivo, donde evalúan las características clínicas e histológicas de 20 pacientes con NIgA y ANCA y se comparan con 40 pacientes con NIgAANCA negativos y con otros 40 con vasculitis sistémica asociada a $\mathrm{ANCA}^{16}$. Los pacientes con NIgA-ANCA positivo, al igual que los de vasculitis ANCA, eran mayores (entre 50-60 años) y presentaban con mayor frecuencia síntomas generales y compromiso pulmonar que el grupo de NIgA-ANCA negativo. No se encontraron diferencias en el porcentaje de glomérulos con semilunas, pero sí mayor porcentaje de necrosis fibrinoide en NIgA-ANCA positivo y vasculitis ANCA. Nueve de 20 pacientes con NIgA-ANCA cursaban con NIgAc (semilunas en $>50 \%$ de glomérulos). Se compararon los pacientes con GNc en los tres grupos, encontrando edad similar en NIgAc con y sin ANCAS, pero mayor edad comparados con GNc-ANCA (54-59 vs. 40 años, $\mathrm{p}=0,001$ ). Los síntomas sistémicos y el compromiso pulmonar fueron más frecuente en NIgAc-ANCA que NIgAc-ANCA negativo. No se encontraron diferencias en la tasa de filtración glomerular (TFG) en los tres grupos. Se suspendió la diálisis en $75 \%$ de pacientes (3/4) con NIgAc-ANCA, comparado con $9,1 \%(1 / 11)$ con NIgAc-ANCA negativo $(\mathrm{p}=0,03), \mathrm{y}$ se evidenció menor progresión a ERC5 a los 6 meses en NIgAc-ANCA. Sin embargo, no se documentaron diferencias en este último desenlace al final del seguimiento $(p=0,11)^{16}$. Este estudio concluye que la presentación de pacientes con NIgA-ANCA mezcla características de la NIgA y de vasculitis ANCA y tiene un curso clínico e histológico más agresivo que los pacientes con NIgA-ANCA negativos. Hay que analizar con cautela los desenlaces de suspensión de diálisis y progresión a ERC5, ya que en este estudio los pacientes ANCA negativo recibieron tratamiento inmunosupresor con menor frecuencia y tenían mayor proporción de glomérulos escleróticos en las biopsias, lo cual puede afectar la interpretación de los resultados.
A pesar de que la aparición de NIgAc es rara, su curso agresivo justifica conocer los factores que predicen pronóstico renal. Jicheng Lv y colaboradores evalúan los desenlaces a largo plazo de una cohorte de 113 pacientes con NIgAc (ANCA negativos) y construyen un modelo de predicción de recuperación renal. La creatinina sérica promedio, en el momento de la biopsia, era 4,3 +/- 3,4 mg/dL. La sobrevida renal, a 1,3 y 5 años después de la biopsia, fue de 57,4 \%, 45, 8\% y $30,4 \%$, respectivamente. El análisis multivariado documenta que la creatinina sérica inicial es el único factor independiente asociado a ERC5 (HR 1,32; 95 $\%$ IC, $1,1-1,57 ; p=0,002)$, sin encontrar efecto del porcentaje de glomérulos crescénticos. El riesgo de ERC5, un año después de la biopsia, aumenta rápidamente con creatinina de $2,7 \mathrm{mg} / \mathrm{dL}$, y es del $90 \%$ con creatinina de $6,8 \mathrm{mg} / \mathrm{dL}$ (sensibilidad $98,5 \%$, especificidad $64,6 \%$ ). Con este último, la posibilidad de recuperación renal es aún más baja, incluso con tratamiento inmunosupresor agresivo ${ }^{17}$.

No existen estudios aleatorizados que permitan conocer cuál es el tratamiento ideal para la NIgAc, sino casos y series reportados en la literatura, donde se extrapola el tratamiento de las otras GNc y vasculitis pauci-inmune, como el uso de esteroides y ciclofosfamida, con resultados variables ${ }^{4,16-18}$. De hecho, las guías KDIGO de 2011 sugieren no tratar pacientes con NIgA con corticoesteroides combinados con ciclofosfamida o azatioprina, a menos que cursen con NIgAc y deterioro rápido de la función renal (recomendación 2D) ${ }^{19}$. La plasmaféresis ha sido usada en pacientes con NIgAc. Los autores que realizan el estudio, referenciado previamente, del modelo de predicción de recuperación renal ${ }^{17}$, instauran en su práctica clínica la plasmaféresis en pacientes con NIgAc con creatinina mayor a $6,8 \mathrm{mg} / \mathrm{dL}$ (punto de no retorno documentado en su análisis inicial), con requerimiento de diálisis o deterioro persistente de función renal a pesar de recibir esteroides u otros inmunosupresores. Publican los resultados de 12 
pacientes con plasmaféresis, comparados con un grupo control escogido por análisis de propensión. Durante el seguimiento (promedio de 15 meses), el $50 \%$ de pacientes con plasmaféresis queda libre de diálisis comparado con $0 \%$ del grupo control20. Adicionalmente, se documentó disminución de inmunocomplejos IgA-IgG circulantes y de productos de activación del complemento ${ }^{20}$.

También vale la pena nombrar la asociación que existe entre NIgA y la activación del complemento, ya que se han encontrado mutaciones y polimorfismos de genes que codifican el factor $\mathrm{H}$ y las proteínas relacionadas con el factor $\mathrm{H}$ en este grupo de pacientes ${ }^{3}$. El depósito de $\mathrm{C} 3$ y $\mathrm{C} 4$, en las biopsias renales de NIgA, sugiere la activación de la vía alternativa y de las lectinas. Desde el punto de vista clínico, el depósito de $\mathrm{C} 4 \mathrm{~d}$ en el mesangio y C3d en células peritubulares se ha asociado a formas agresivas de la enfermedad ${ }^{21,22}$. Ya se han evaluado bloqueadores del complemento en pacientes con nefritis lúpica y vasculitis ANCA e incluso se reportó el uso de eculizumab en un paciente NIgA refractaria a esteroide, ciclofosfamida y plasmaféresis ${ }^{23-25}$. Seguramente, hasta que se realicen estudios prospectivos y aleatorizados que permitan evaluar la efectividad de este tipo de tratamientos en pacientes con NIgAc, seguirán considerandose los esteroides, otros inmunosupresores y la plasmaféresis como algunas opciones terapéuticas en este grupo de alto riesgo.

\section{Discusión}

El caso que presentamos pone en evidencia las diferentes presentaciones clínicas de la NIgA, puesto que el paciente cursaba con ERC y, posteriormente, síndrome nefrótico y lesión renal aguda. A pesar de que la biopsia fue de escaso material, se logra evidenciar la presencia de semilunas, concordante con el comportamiento clínico del paciente. No fue posible realizar inmunofluorescencia, pero la inmunohistoquímica es positiva para $\operatorname{IgA}$ en el mesangio, corroborando la NIgA diagnosticada previamente. Basados en el deterioro agudo y severo de la función renal, se inicia esteroide y ciclofosfamida, como ha sido descrito en algunas series de caso referenciadas. Posteriormente, por la documentación de las semilunas, la positividad de ANCA-MPO y la elevación de la creatinina sérica, se inicia plasmaféresis, logrando detener el deterioro de la función renal, pero con persistencia de la proteinuria nefrótica. El escaso tiempo de seguimiento del paciente no nos permite conocer el desenlace final.

Con base en la revisión de la literatura realizada, conviene resaltar que, a pesar de no estar claro el rol patogénico de los ANCA en NIgA, el deterioro renal de este paciente coincide con la aparición de semilunas y ANCAno documentados anteriormente. No se encontró necrosis fibrinoide (uno de los hallazgos característicos de las vasculitis ANCA), ni tampoco refería síntomas sistémicos ni compromiso pulmonar, como lo hacen estos pacientes. Si bien la presencia de necrosis fibrinoide es frecuente en las biopsias de pacientes con NIgAc-ANCA, no en todos los casos reportados en la literatura se presenta este hallazgo ${ }^{16}$.

Hasta el momento, no hay suficiente evidencia que defina el real significado de los ANCA en pacientes con NIgA. Sin embargo, los datos de los estudios descritos previamente sugieren que: los pacientes con NIgA-ANCA tienen características clínicas similares a los pacientes con vasculitis ANCA; tienen hallazgos histológicos diferentes a los presentados en NIgA-ANCA negativos; y cursan con frecuencia con GNc. El pronóstico renal de los pacientes con NIgAc-ANCA, en comparación con NIgAc-ANCA negativos, no es claro, en la medida que los estudios realizados hasta el momento no permiten concluir datos exactos acerca de este tema. La GNc en IgA ha sido definida de diferentes formas en los estudios (diferente porcentaje de glomérulos con semilunas) y no se ha evaluado la 
respuesta a tratamientos específicos comparados con un grupo control. En estudios descriptivos, los pacientes con NIgAc-ANCA han sido tratados con esquemas inmunosupresores usados en pacientes con vasculitis ANCA, documentándose respuesta clínica en algunos de ellos ${ }^{15}$.

Aunque no hay suficiente evidencia científica que permita predecir el desenlace renal en nuestro paciente, es probable que presente progresión, teniendo en cuenta su función renal basal, la proteinuria persistente y el nivel de creatinina alcanzado. Este es un caso que demuestra un curso agresivo de la enfermedad, con una presentación poco frecuente, como es la GNc, y en quien el hallazgo de ANCA obliga a preguntarse si es una coincidencia o una enfermedad adicional.

\section{Conclusión}

La nefropatía por $\operatorname{IgA}$ es una enfermedad que puede tener, eventualmente, un curso agresivo, con glomerulonefritis rápidamente progresiva $\mathrm{y}$, adicionalmente, coexistencia de ANCA. No es claro el rol patogénico de los ANCA en la nefropatía por IgA. Sin embargo, el hecho de que los pacientes con ANCA se presenten clínica e histológicamente diferente a los ANCA negativos, en las series de caso descritas en este texto, sugiere que puedan ser entidades diferentes.

Es importante evaluar la presencia de ANCA en pacientes con NIgA de curso no habitual, deterioro acelerado y/o con semilunas en la biopsia renal. En caso de documentar NIgAc y ANCA, se sugiere buscar manifestaciones extrarrenales de vasculitis e iniciar tratamiento inmunosupresor agresivo, según sea el caso. Se espera que, con la realización de estudios en el futuro, logremos conocer cuál es la aproximación diagnóstica e intervención terapéutica más acertada en este grupo de pacientes.

Institución donde se lleva a cabo el trabajo: Hospital Militar Central, Bogotá, Colombia.

\section{Conflicto de intereses}

Los autores declaran no tener conflicto de intereses en la realización de este artículo.

\section{Responsabilidades éticas}

\section{Protección de personas y animales}

Los autores declaran que para esta investigación no se han realizado experimentos en seres humanos ni en animales.

\section{Confidencialidad de los datos}

Los autores declaran que en este artículo no aparecen datos de pacientes.

\section{Derecho a la privacidad y consentimien- to informado}

Los autores declaran que en este artículo no aparecen datos de pacientes.

\section{Contribución de los autores}

Jorge Echeverri, Adalberto Pecha y Carolina Larrarte: realizaron la revisión de la historia clínica del paciente, actualizaron la información, realizaron la revisión de la literatura correspondiente y realizaron el escrito.

Luis Javier Ossa, José de Jesús Arias y Diana Gutiérrez: revisaron las placas de histología de la biopsia renal, revisaron el caso, y reportaron la patología en el escrito.

Todos los autores revisaron el escrito al final y aprobaron el resultado.

Peña Wilches A, Arias Agudelo J, Ossa Gómez LJ, Gutiérrez González D, Echeverri Sarmiento JE, et al 


\section{Referencias}

1. Floege J, Feehally J. IgA nephropathy: recent developments. J Am Soc Nephrol. 2000;11(12):2395-403.

2. Coppo R, D’Amico G. Factors predicting progression of IgA nephropathies. J Nephrol. 2005;18(5):503-12.

3. Rojas-Rivera J, Fernandez-Juarez G, Praga M. Rapidly progressive IgA nephropathy: a form of vasculitis or a complement-mediated disease? Clin Kidney J. 2015;8(5):477-481. Disponible en: https://doi.org/10.1093/ckj/sfv095

4. Bantis C, Stangou M, Schlaugat C, Alexopoulos E, Pantzaki A, Memmos D, et al. Is presence of ANCA in crescentic IgA nephropathy a coincidence or novel clinical entity? A case series. Am J Kidney Dis. 2010;55(2):259-68. Disponible en: https://doi. org/10.1053/j.ajkd.2009.09.031

5. Huang X, Wang Y, Xie L, Zhang Y, Tang S, Yin S, et al. IgA nephropathy with anti-neutrophil cytoplasmic antibody seropositivity. Clin Nephrol. 2015;84(3):156-64. Disponible en: https://doi.org/10.5414/CN108571

6. Ozaltin F, Bakkaloglu A, Ozen S, Topaloglu R, Kavak U, Kalyoncu M, et al. The significance of IgA class of antineutrophil cytoplasmic antibodies (ANCA) in childhood Henoch-Schönlein purpura. Clin Rheumatol. 2004;23(5):426-9. Disponible en: https://doi.org/10.1007/s10067-004-0910-y

7. Ronda N, Esnault VL, Layward L, Sepe V, Allen A, Feehally J, et al. Antineutrophil cytoplasm antibodies (ANCA) of IgA isotype in adult Henoch-Schönlein purpura. Clin Exp Immunol. 1994;95(1):49-55. Disponible en: https://doi.org/10.1111/j.1365-2249.1994. $\underline{\text { tb06013.x }}$

8. Ara J, Bonet J, Rodríguez R, Mirapeix E, Agraz I, Romero R. IgA nephropathy with crescentic glomerulonephritis and ANCA positive. Nefrologia. 2005;25(6): 712-7.

9. Martin SJ, Audrain MA, Baranger T, Moreau A, Dantal J, Testa A, et al. Recurrence of immunoglobulin A nephropathy with immunoglobulin A antineutrophil cytoplasmic antibodies following renal transplantation. Am J Kidney Dis. 1997;29(1):125-31. Disponible en: https://doi.org/10.1016/S0272-6386(97)90019-6

10. Bollee G, Noel LH, Suarez F, Royal V, Gilardin L, de Serre NP, et al. Pauci-immune crescentic glomerulonephritis associated with ANCA of IgA class. Am J Kidney Dis. 2009;53(6):1063-7. Disponible en: https://doi.org/10.1053/j.ajkd.2008.10.039

11. O’Donoghue DJ, Nusbaum P, Noel LH, Halbwachs-Mecarelli L, Lesavre P. Antineutrophil cytoplasmic antibodies in IgA nephropathy and Henoch-Schönlein purpura. Nephrol Dial Transplant. 1992;7(6):534-8.

12. Allmaras E, Nowack R, Andrassy K, Waldherr R, van der Woude F, Ritz E. Rapidly progressive IgA nephropathy with anti-myeloperoxidase antibodies benefits from immunosuppression. Clin Nephrol. 1997;48(5): 269-73.

13. Ramirez SB, Rosen S, Niles J, Somers MJ. IgG antineutrophil cytoplasmic antibodies in IgA nephropathy: a clinical variant? Am J Kidney Dis. 1998;31(2):341-4. Disponible en: https://doi.org/10.1053/ajkd.1998.v31.pm9469508

14. Haas M, Jafri J, Bartosh SM, Karp SL, Adler SG, Meehan SM. ANCA-associated crescentic glomerulonephritis with mesangial IgA deposits. Am J Kidney Dis. 2000;36(4):709-18. Disponible en: https://doi.org/10.1053/ajkd.2000.17615

15. Bantis C, Stangou M, Schlaugat C, Alexopoulos E, Pantzaki A, Memmos D, et al. Is presence of ANCA in crescentic IgA nephropathy a coincidence or novel clinical entity? A case series. Am J Kidney Dis. 2010;55(2):259-68. Disponible en: https://doi. org/10.1053/j.ajkd.2009.09.031

16. Yang YZ, Shi SF, Chen YQ, Chen M, Yang YH, Xie XF, et al. Clinical features of IgA nephropathy with serum ANCA positivity: a retrospective case-control study. Clin Kidney J. 2015;8(5):482-8. Disponible en: https://doi.org/10.1093/ckj/sfv078

17. Lv J, Yang Y, Zhang H, Chen W, Pan X, Guo Z, et al. Prediction of outcomes in crescentic IgA nephropathy in a multicenter cohort study. J Am Soc Nephrol. 2013;24(12):2118-25. Disponible en: https://doi.org/10.1681/ASN.2012101017

18. Tumlin JA, Hennigar RA. Clinical presentation, natural history, and treatment of crescentic proliferative IgA nephropathy. Semin Nephrol. 2004;24(3):256-68. Disponible en: https://doi.org/10.1016/j.semnephrol.2004.01.006

19. KDIGO clinical practice guideline for glomerulonephritis. Kidney Int Suppl. 2012;2(2):139-274. Chapter 10, Immunoglobulin A nephropathy; p. 209-17. Disponible en: https://doi.org/10.1038/kisup.2012.23 
20. Xie X, Lv J, Shi S, Zhu L, Liu L, Chen M, et al. Plasma Exchange as an Adjunctive Therapy for Crescentic IgA Nephropathy. Am J Nephrol. 2016;44(2):141-9. https://doi.org/10.1159/000448767

21. Espinosa M, Ortega R, Sanchez M, Segarra A, Salcedo MT, Gonzalez F, et al; Spanish Group for Study of Glomerular Diseases (GLOSEN). Association of C4d deposition with clinical outcomes in IgA nephropathy. Clin J Am Soc Nephrol. 2014;9(5): 897904. Disponible en: https://doi.org/10.2215/CJN.09710913

22. Gherghiceanu M, Penescu M, Mandache E. The predictive value of peritubular capillaries C3d deposition in IgA glomerulonephritis. J Cell Mol Med. 2005;9(1):143-52. Disponible en: https://doi.org/10.1111/j.1582-4934.2005.tb00344.x

23. Coppo R, Peruzzi L, Amore A, Martino S, Vergano L, Lastauka I, et al. Dramatic effects of eculizumab in a child with diffuse proliferative lupus nephritis resistant to conventional therapy. Pediatr Nephrol. 2015;30(1):167-72. Disponible en: https://doi. org/10.1007/s00467-014-2944-y

24. Jayne DRW, Bruchfeld A, Schaier M, Ciechanowski K, Harper L, Jadoul M, et al. Glomerulonephritides. Phase 2 randomised trial of oral C5a receptor antagonist CCX168 in ANCAassociated renal vasculitis. Nephrol Dial Transplant. 2014;29(Suppl 3):iii27-9. Disponible en: https://doi.org/10.1093/ndt/gfu120

25. Ring T, Pedersen BB, Salkus G, Goodship TH. Use of eculizumab in crescentic IgA nephropathy: proof of principle and conundrum? Clin Kidney J. 2015;8(5):489-91. Disponible en: https://doi.org/10.1093/ckj/sfv076 